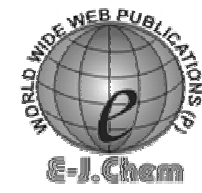

http://www.e-journals.net
ISSN: 0973-4945; CODEN ECJHAO

E-Journal of Chemistry

Vol. 1, No. 1, pp 51-56, March 2004

\title{
Synthesis and Characterization of Colored Polyureas
}

\author{
M. G. PATEL, K. R. DESAI* and H.S. PATEL ${ }^{\#}$ \\ Department of Chemistry, South Gujarat University, Surat. (Gujarat), India. \\ ${ }^{\#}$ Department of Chemistry, Sardar Patel University, Vallabh Vidyanagar. (Gujarat)
}

Received 20 February 2004; Accepted 24 February 2004

\begin{abstract}
Various disperse dyes based on $m$-phenylenediamine have been prepared. These dyes then polycondensation with 4, 4'-Diphenyl methane diisocyanate. The resultant colored polyureas were characterized by $\mathrm{N}$ content, IR spectral studies, Number Average Molecular Weight (Mn) estimation by nonaqueous conductometric titration and thermogravimetry. All the polyureas were subjected to measure electrical conductivity at room temperature.
\end{abstract}

Keywords: Polyurethanes, IR spectral studies, Number average molecular weight (Mn) Thermogravimetric, Electrical conductivity.

\section{Introduction}

Polyureas may be classified as heterochain macromolecular compounds, which contain urea groups in their structure. Although the chemistry and technology of polyureas are of recent origin, the chemistry of ureas dates back over 100 years. Linear polyureas are thermoplastic polycondensation products with aliphatic or aromatic structures. Polyureas or copolyureas containing aliphatic structures exhibit a different temperature of $50-100^{\circ} \mathrm{C}$ between melting points and the beginning of decomposition; they are used for castings. Polyureas containing aromatic structures melt near their decomposition temperatures. They are soluble in some organic solvents and can be used for preparation of lacquers, varnishes and coating. ${ }^{1}$ Melting points also depend on the molecular weight. Molecular weights are determined from the measurements of the solution viscosity. The inherent viscosity ranges from 0.5 to $2 \mathrm{dL} / \mathrm{g}$. The relation between intrinsic viscosity and molecular weight has been investigated using the Mark - Houwink equation ${ }^{2}$.

Polyureas were first prepared on a commercial scale at I.G. Farben, employing the reaction between diisocyanates and diamines. Mitsui Toatsu Chemical Ltd. Produces synthetic fibers from nonamethylenediamine and urea. Today, polyureas and copolyureas (especially polyurethane polyureas) have many practical applications as foam, elastomers, adhesives, fibers and other ${ }^{3}$. 
The area in which the colored polyurea has not received attention academically even the number of dye containing diamino groups (i.e. capable for reaction with diisocyanate). Hence, it was thought interesting to explore the field of colored polyureas. The present paper comprises synthesis, characterization and electrical conductivity of polyureas. The research work is scanned in the following scheme.
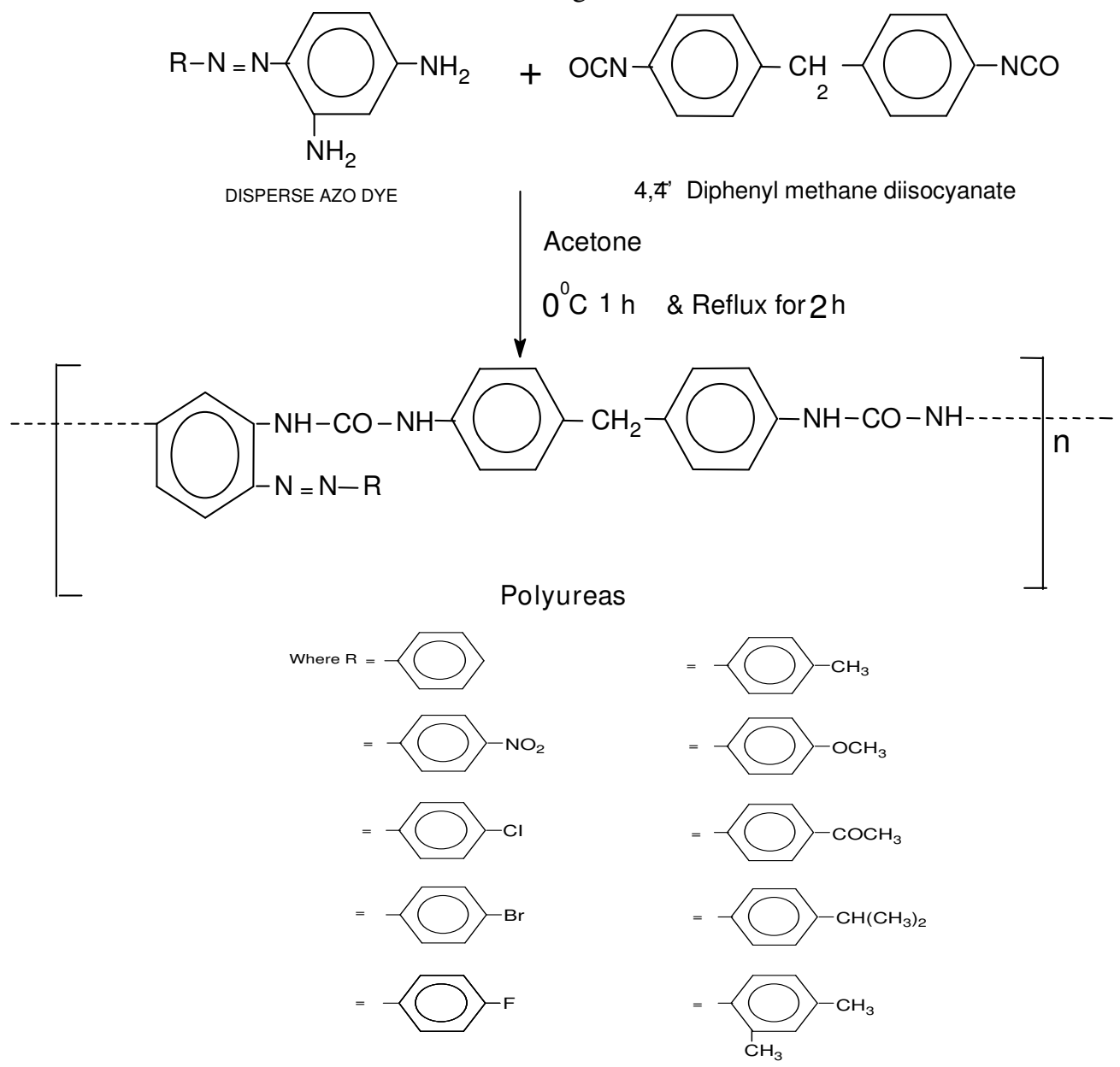

\section{Experimental}

Scheme 1

\section{Materials}

All the chemicals used were of analytical grade.

Synthesis of azo disperse dyes

The azo disperse dyes having structures shown in scheme 1 were prepared by the methods reported in literature ${ }^{4}$.

Synthesis of colored polyureas

All the polyurethane based on azo disperse dyes were prepared in the similar manner. The general process is as follows. 
To an ice cooled solution of azo disperse dye sample (0.01 moles) in dry acetone $(50 \mathrm{~mL})$ a solution of $4,4^{\prime}$-Diphenyl methane diisocyanate, $(0.01 \mathrm{~mole})$ in $50 \mathrm{~mL}$ dry acetone was added gradually with constant stirring. The colloidal suspension was formed immediately which was then stirred at room temperature for an hour. The resultant suspension was refluxed $\left(\sim 60^{\circ} \mathrm{C}\right)$ for $2 \mathrm{~h}$ on a water bath. The resulting solid product was then filtered off and air-dried (95\% yields).

\section{Measurements}

$\mathrm{C}, \mathrm{H}, \mathrm{N}$ contents of all polyureas samples were estimated by $\mathrm{C}, \mathrm{H}, \mathrm{N}, \mathrm{O}$ and $\mathrm{S}$ elemental analyzer, Carlo Erba, Italy. The $\overline{\mathrm{IR}}$ spectra of polymers were scanned in $\mathrm{KBr}$ pellets on Perkin Elemer 257 spectrophotometer, Number average molecular weights of PURs were estimated by non-aqueous conductometric titration. The titration was carried out in formic acid against perchloric acid as titrant. Digital conductometre, Toshniwal, India was used for this purpose. The values of number average molecular weight of all polymer samples were calculated following the method reported by one of the author $[\mathrm{HSP}]^{5}$. Thermo gravimetric analyses for polymers were carried out on Du Pont thermo balance in air at a heating rate of $10 \mathrm{~K} \mathrm{~min}^{-1}$. The electrical conductivity of each of PURs sample was measured on pellets $\left(1 \mathrm{~cm}\right.$ diameter, $0.45 \mathrm{~cm}$ thickness) at room temperature $\left(30 \pm 1^{\circ} \mathrm{C}\right)$ using a Million Megohmmeter RM 160 MK IIA BPL, India. The preparations of the pellets of all the PURs samples and other details have been described in an earlier communication. ${ }^{6}$

\section{Results and Discussion}

The polyureas (PURs) formation is performed by facile reaction of $-\mathrm{NH}_{2}$ groups dye moiety with -NCO groups. All PURs shown in scheme 1 are furnished in Table I. They are found to be colored solid powders. They do not melt up to $250^{\circ} \mathrm{C}$ and are insoluble in common organic solvents. ( $\mathrm{C}, \mathrm{H}, \mathrm{N}$ ) (Table I) of each of the PURs are consistent with the corresponding predicted structure (reaction scheme).

IR spectra (not shown) of all the PURs are identical in almost in all aspects and inspection of all the spectral revalues that all the spectra comprise important IR spectral features of urea linkages. The IR bands at $1620-1280 \mathrm{~cm}^{-1}, 1240-1250 \mathrm{~cm}^{-1}$ may be respectively due to urea linkage. The other IR spectra feature are due to aromatic and aliphatic segments of monomers are appeared at their respective positions.

As the produced polymers are insoluble in organic solvents, the colligative properties (i.e. viscosity, osmometry) have not been studied hence the number average molecular weight $(\overline{\mathrm{Mn}})$ of all the polymer sample has been measured by end group $-\mathrm{NH}_{2}$ by nonaqueous conductometric titration. The results of number average molecular weight values are furnished in Table I.

Typical TG thermogram of PUR is shown in Figure 1. Inspections of the TG thermograms are reveals that all the PUR decomposed in one step. They start their degradation about $200^{\circ} \mathrm{C}$, losses their weight rapidly between 200 to $600^{\circ} \mathrm{C}$.

The electrical conductivity measured at room temperature of all PURs samples are shown in Table II and they are in the range of $6.2 \times 10^{-10}$ to $3.8 \times 10^{-7} \Omega \mathrm{cm}^{-1}$ depending upon the nature of polymer. The examination of the results reveals that the produced PURs can be ranked as poor insulators. The application of PURs is under investigation. 
Table-I Characterization of polyureas (PURs)

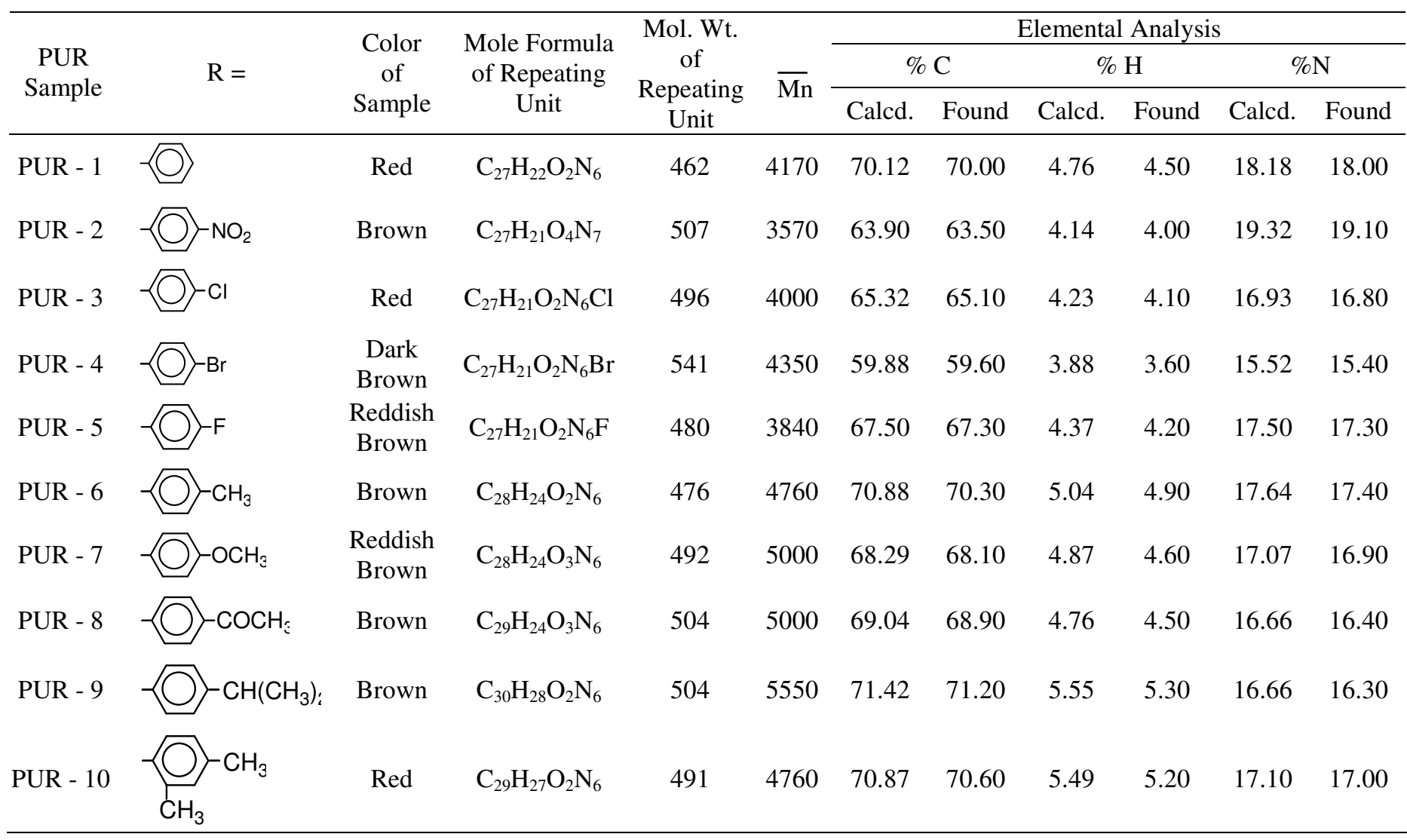


Table II. Electrical conductivity of PURs

\begin{tabular}{cc}
\hline PUR samples & $\begin{array}{c}\text { Electrical conductivity }(\sigma) \text { at } 303^{\circ} \mathrm{K} \\
\left(\Omega \cdot \mathrm{cm}^{-1}\right)\end{array}$ \\
\hline PUR - 1 & $4.2 \times 10^{-8}$ \\
PUR - 2 & $6.2 \times 10^{-10}$ \\
PUR - 3 & $9.2 \times 10^{-9}$ \\
PUR - 4 & $4.8 \times 10^{-9}$ \\
PUR - 5 & $6.6 \times 10^{-9}$ \\
PUR - 6 & $3.8 \times 10^{-7}$ \\
PUR - 7 & $7.6 \times 10^{-7}$ \\
PUR - 8 & $8.1 \times 10^{-7}$ \\
PUR - 9 & $4.7 \times 10^{-7}$ \\
PUR - 10 & $5.8 \times 10^{-7}$ \\
\hline
\end{tabular}

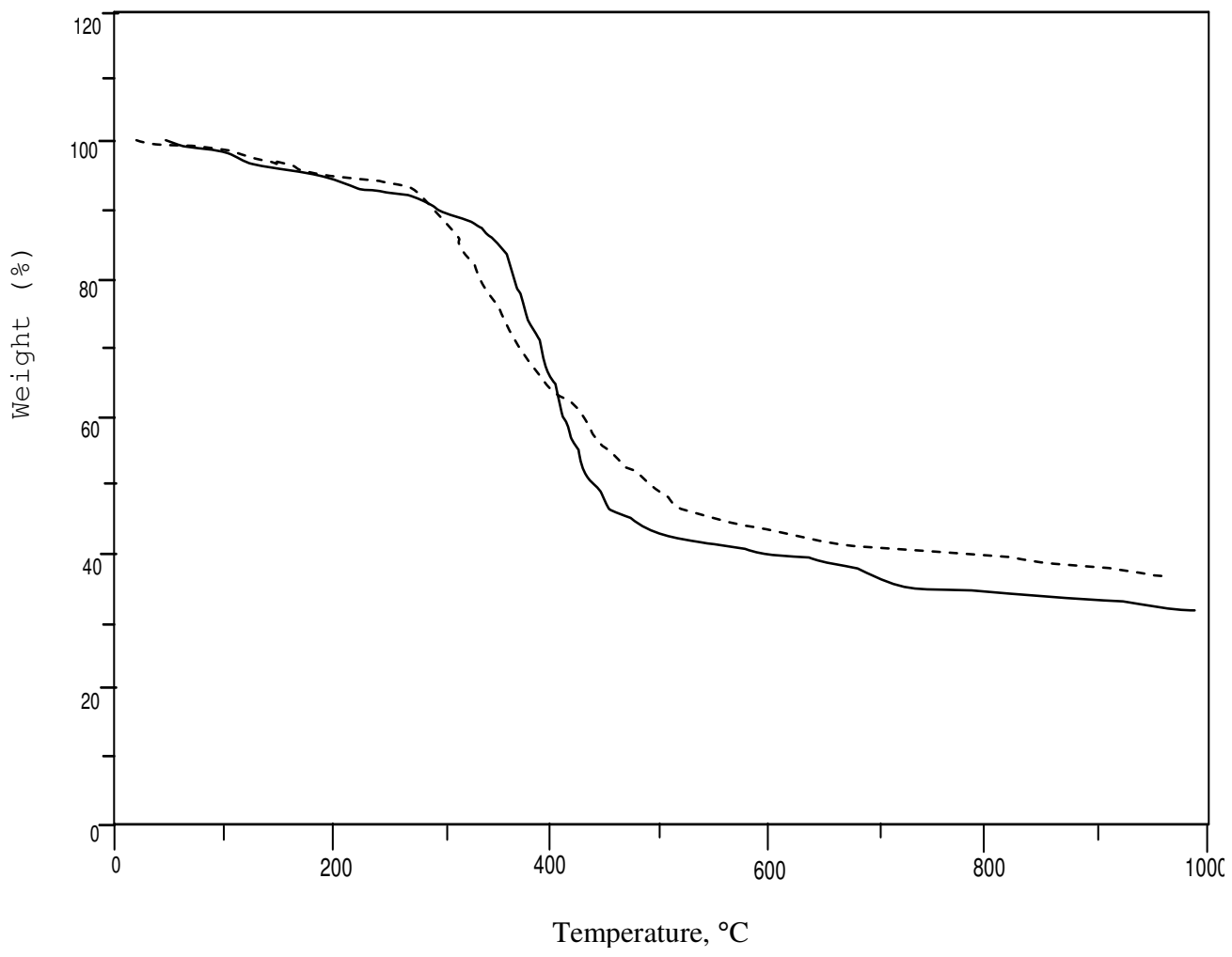

Figure 1. TG thermogram of polyureas (PURs) 


\section{Conclusion}

The present work is colored polyureas. The nature of theses polymer is amorphous colored powder. They have good thermal stability. Having urea groups they can compatible to the thermoplast and can be easily form the colored article even though article processed at high temperature. Looking to the properties of colored polyureas they can not be bloom or bleed from the articles.

\section{Acknowledgement}

The authors are thankful to the Atul Products Ltd, ATUL for providing chemicals and Garda Chemicals, Panoli GIDC, ANKLESWER for providing the thermal studies. The authors are also thankful to SOUTH GUJARAT UNIVERSITY, SURAT for providing the research facility.

\section{References}

1. Scholl R and Holdermann, K, Ann, 1907, 345, 375.

2. Feist J and Elias H G, Macromol Chem, 1965, 82, 78.

3. Baker J and Bailey D N J Chem Acta, 1938, 21, 1127.

4. Desai C K and Desai K R, Iranian Polymer, J 2000, 9, 3.

5. Patel H S and Brahmbatt D I Pos Sulfur Silicon, 1992, 73, 57.

6. Patel K B, Desai K R and Patel H S Intern J Polymeric Mater, 1997, 35, 137. 


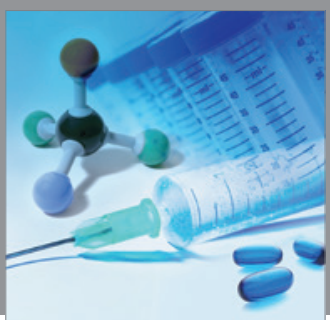

International Journal of

Medicinal Chemistry

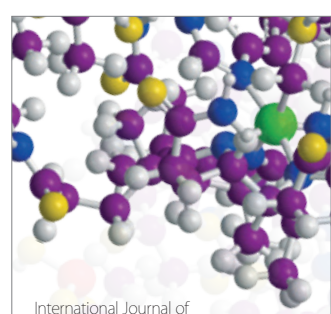

Carbohydrate Chemistry

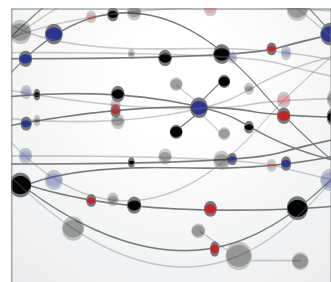

The Scientific World Journal
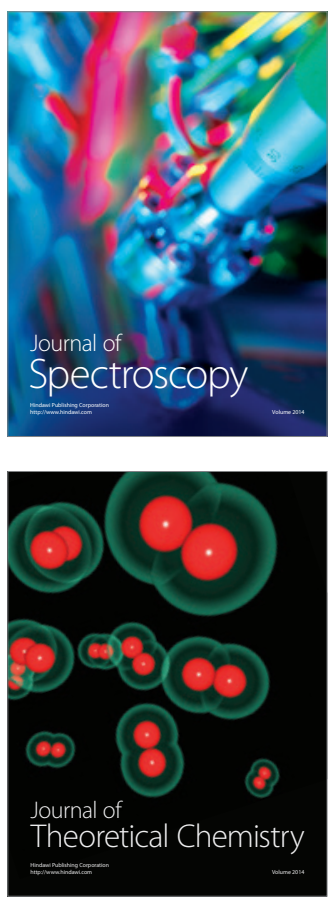
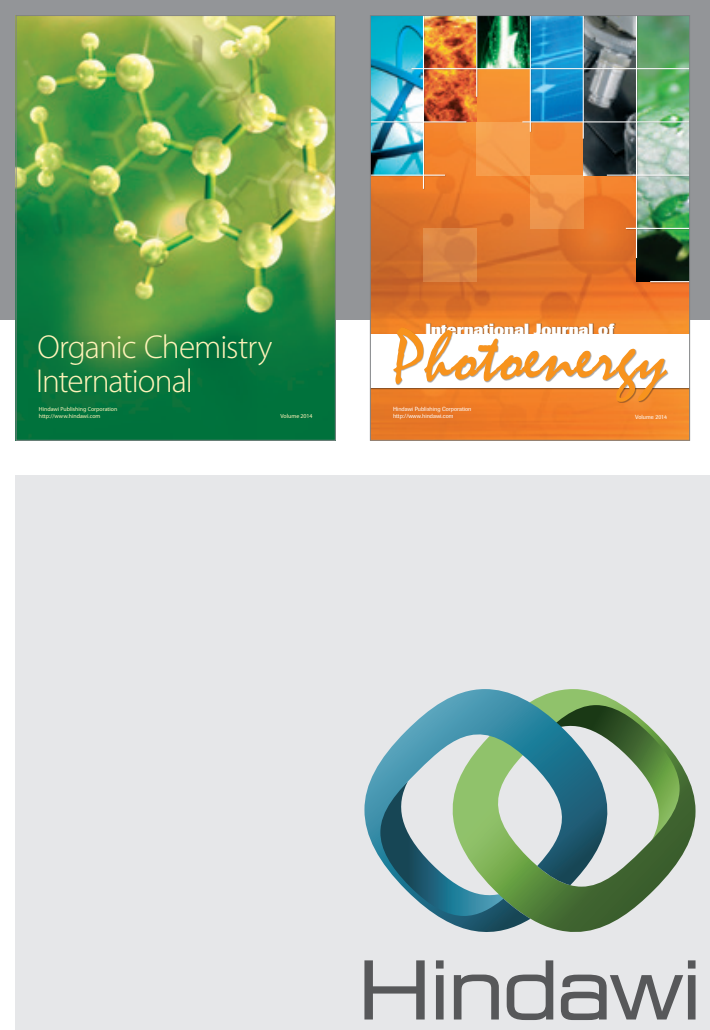

Submit your manuscripts at

http://www.hindawi.com
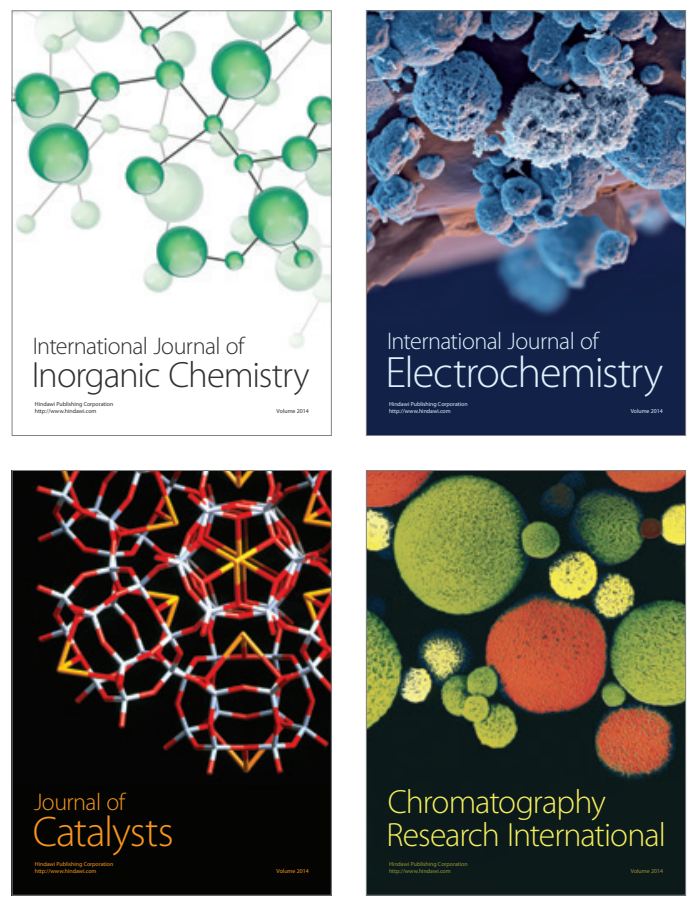
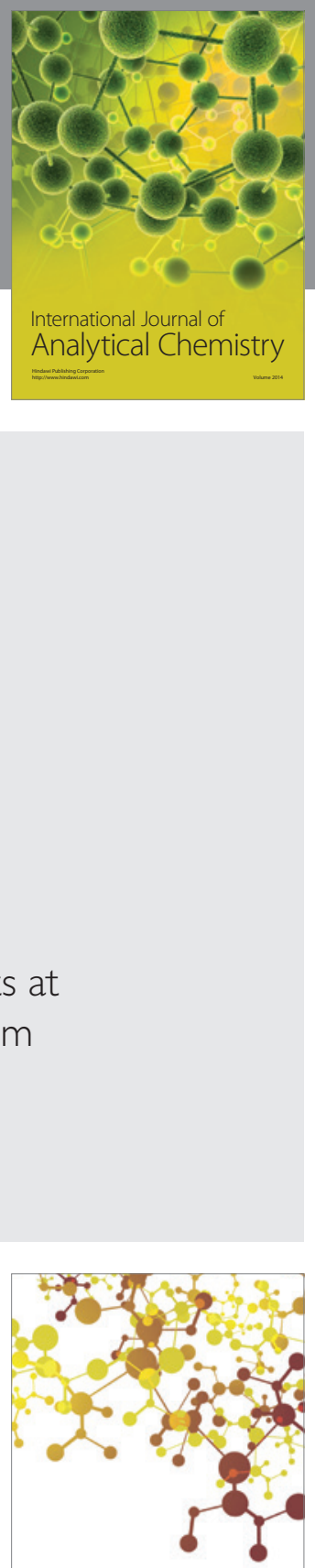

Journal of

Applied Chemistry
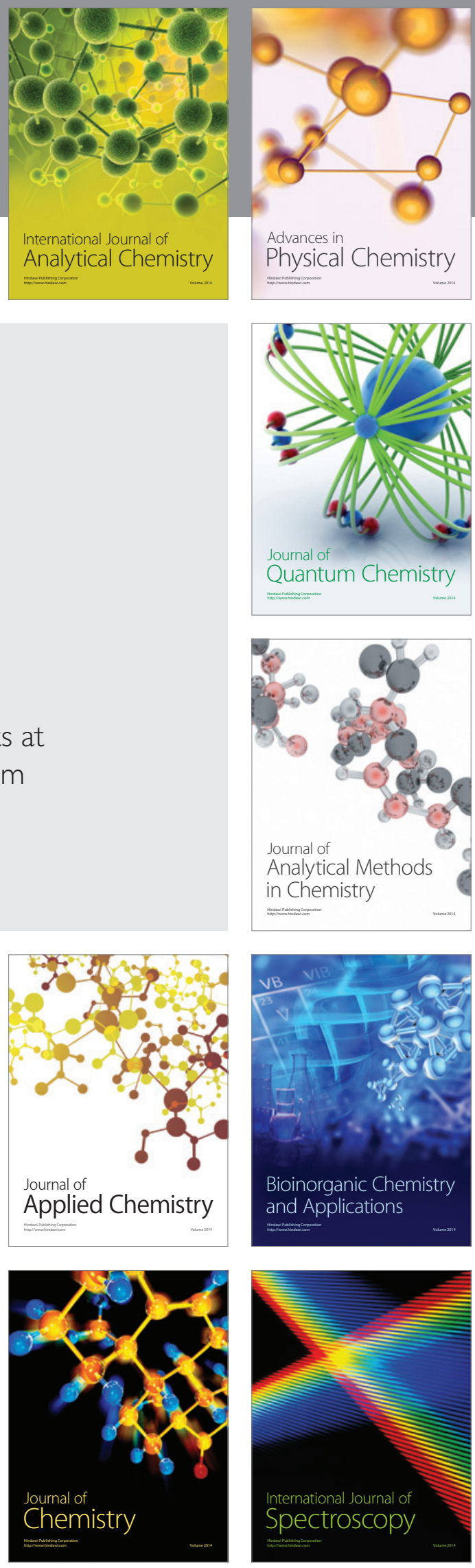